\title{
Severe Neck Pain in Older Patients
}

\author{
Kobayashi $\mathrm{T}^{1^{*}}$, Miyakoshi $\mathrm{N}^{2}$ and Shimada $\mathrm{Y}^{2}$
}

${ }^{1}$ Departments of Orthopedic Surgery, Akita Kousei Medical Center, Akita 011-0948, Japan

${ }^{2}$ Department of Orthopedic Surgery, Akita University Graduate School of Medicine, Akita 010-8543, Japan

*Corresponding author: Kobayashi T, Department of Orthopedic Surgery, Akita Kousei Medical Center, lijima-Nishifukuro, Akita 011-0948, Japan, Tel: +81-18-880-3000; Fax: +81-18-880-3040; E-mail: takakoba825@hotmail.com

Received date: Jan 02, 2017; Accepted date: Jan 20, 2017; Published date: Jan 27, 2017

Copyright: (c) 2017 Kobayashi T, et al. This is an open-access article distributed under the terms of the Creative Commons Attribution License, which permits unrestricted use, distribution, and reproduction in any medium, provided the original author and source are credited.

\begin{abstract}
Many of the diseases can cause severe neck pain in older patients. $10 \%$ of people will have neck pain in a life time. The most common causes are axial pain, whiplash-associated disorder, and cervical radiculopathy. Most cases without trauma, motor and/or sensory changes, and radiological abnormalities were diagnosed as axial pain. To date, crowned dens syndrome (CDS) and acute calcific retropharyngeal tendinitis (ACRT) have been almost considered as the main causes of acute neck pain in the elderly without trauma.
\end{abstract}

Keywords: Acute neck pain; Lateral atlanto-axial joint; Pseudogout; Calcification; Calcium pyrophosphate dihydrate; Crowned dens syndrome; Acute calcific retropharyngeal tendinitis

\section{Introduction}

CDS was first reported by Bouvet et al. as a cause of acute neck pain with calcification around the odontoid process [1-4]. However, Finckh et al. reported that even when CT revealed calcification around the odontoid process of patients complaining of acute neck pain, such calcification was not directly related to the pain, because cervical calcifications were also found in $11 \%$ of the control group [5-8]. ACRT was first reported by Hartley. Ring et al. [6] biopsied the anterior vertebral body of patients with ACRT and documented that inflammation was due to foreign-body reactions to hydroxyapatite crystals in the tendon of the longus colli muscle [7].

\section{Methods}

As many of our patients are limited in rotation, we suspected the lateral atlanto-axial joint as a likely cause of pain and performed lateral atlanto-axial joint puncture. We conducted the prospective study mainly based on the hypothesis that arthritis of the lateral atlanto-axial joint may be involved in severe neck pain in older patients with limited neck rotation [9].

A total of 27 patients $\geq 50$ years old who provided consent for atlanto-axial joint puncture was included in this study. The inclusion criteria was as followed:

1. Severe neck pain with limited cervical rotation less than $20^{\circ}$ as the chief complaint.

2. Visual analog scale (VAS) pain score $\geq 70 \mathrm{~mm}$ at initial visit.

3. Tenderness in the paraspinal muscle of upper cervical region.

4. C-reactive protein level $\geq 0.5 \mathrm{mg} / \mathrm{dl}$. Patients underwent aspiration of the lateral atlanto-axial joint and were evaluated clinically and mainly radiologically.

Computed tomography (CT) obtained as before puncture showed calcification of the transverse ligament of the atlas in the posterior dens mainly like CDS in 22 patients (81.5\%), calcification in the tendon of the longus colli like ACRT especially in 2 patients (7.4\%), and no calcification in 3 patients (11.1\%). Of the 27 patients who have underwent lateral atlanto-axial joint aspiration, joint fluid was collected from 16 patients (59.3\%), and calcium pyrophosphate dihydrate (CPPD) crystals were found in 10 patients (62.5\%).

After performing cervical computed tomography (CT), the lateral atlanto-axial joint was punctured on the side with stronger symptoms and local anesthetic was then injected. Mean VAS score before puncture was significantly improving by $30 \mathrm{~min}$ after puncture.

\section{Results and Conclusion}

The results of this study recommend that crystal-induced arthritis (pseudogout) of the lateral atlanto-axial joint may be closely intricated with severe neck pain in older patients. CDS and ACRT may be the diseases associated with the lateral atlanto-axial joint. This entity is considered to be more common than previously suggested and may exist independently from the conventional entities of CDS and ACRT.

\section{References}

1. Lawrence JS (1969) Disc degeneration. Its frequency and relationship to symptoms. Ann Rheum Dis 28: 121-138.

2. Douglass AB, Bope ET (2004) Evaluation and treatment of posterior neck pain in family practice. J Am Board Fam Pract 17: S13-S22.

3. Aouba A, Vuillemin-Bodaghi V, Mutschler C, De Bandt M (2004) Crowned dens syndrome misdiagnosed as polymyalgia rheumatica, giant cell arteritis, meningitis or spondylitis: an analysis of eight cases. Rheumatology (Oxford) 43: 508-512.

4. Bouvet JP, le Parc JM, Michalski B, Benlahrache C, Auquier L (1985) Acute neck pain due to calcifications surrounding the odontoid process: the crowned dens syndrome. Arthritis Rheum 28: 1417-1420.

5. Goto S, Umehara J, Aizawa T, Kokubun S (2007) Crowned dens syndrome. J Bone Joint Surg Am 89: 2732-2736.

6. Hartley J (1964) Acute cervical pain associated with retropharyngeal calcium deposit. A case report. J Bone Joint Surg Am 46: 1753-1754.

7. Ring D, Vaccaro AR, Scuderi G, Pathria MN, Garfin SR (1994) Acute calcific retropharyngeal tendinitis. Clinical presentation and pathological characterization. J Bone Joint Surg Am 76: 1636-1642. 
Citation: Kobayashi T, Miyakoshi N and Shimada Y (2017) Severe Neck Pain in Older Patients. Arch Surg Oncol 3: 118. doi: 10.4172/2471-2671.1000118

Page 2 of 2

8. Finckh A, Van Linthoudt D, Duvoisin B, Bovay P, Gerster JC (2004) The cervical spine in calcium pyrophosphate dihydrate deposition disease. A prevalent case-control study. J Rheumatol 31: 545-549.
9. Kobayashi T, Miyakoshi N, Konno N, Abe E, Ishikawa Y, et al. (2014) Acute neck pain caused by arthritis of the lateral atlantoaxial joint. Spine J 14: 1909-1913. 